Geografia e Ordenamento do Território, Revista Electrónica

Centro de Estudos de Geografia e Ordenamento do Território

http://cegot.org

ISSN :2182-1267

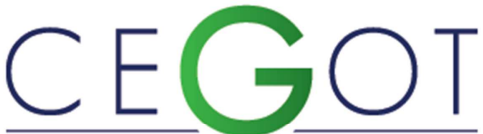

Centro de Estudos de Geografia e Ordenamento do Território
Naveiro, Miriam

Grupo de Estudios Sobre Territorio y Desarrollo Sostenible Departamento de Derecho Público. Campus El Cristo A, C/ Valentín Andrés Álvarez s/n, Edificio Departamentos Jurídicos, 1a planta, 33006 Oviedo

alonso.naveiro.m@gmail.com

\title{
La inclusión de los mapas cognitivas en los sistemas de evaluación ${ }^{1}$
}

Referência: Naveiro, Miriam (2015). La inclusión de los mapas cognitivas en los sistemas de evaluación. (GOT), n.o 7 (junho). Centro de Estudos de Geografia e Ordenamento do Território, p. 251-270, dx.doi.org/10.17127/got/2015.7.011

\section{Resumen}

La Regeneración Urbana Integrada nace como el modelo que pretende trascender los enfoques parciales de los sistemas urbanos para abordar el análisis, el desarrollo de estrategias, y la evaluación desde un enfoque multidisciplinar y con participación activa del ciudadano. Sin embargo, las herramientas o "sistemas de indicadores" desarrollados hasta la actualidad carecen aún de esa visión integrada, manteniendo al ciudadano como mero espectador y no como parte activa del impulso de las políticas de desarrollo. El presente artículo pretende canalizar esta participación del ciudadano y esta visión pluridisciplinar recuperando los sistemas de análisis cualitativos, que a través de mapas cognitivos, complementen los sistemas de indicadores desarrollados hasta la actualidad incorporando la percepción real del usuario sobre la ciudad.

Palabras Clave: regeneración urbana integrada, mapas cognitivos, sistemas cualitativos, participación ciudadana, enfoque multidimensional.

1 Este trabajo ha sido realizado en el marco del Proyecto de Investigación del Ministerio de Ciencia e Innovación "La regeneración urbana integrada como instrumento estratégico para un nuevo modelo de desarrollo urbano más inteligente, sostenible, e inclusivo. Su estatuto jurídico" (DER2011-26446) que dirige la catedrática María Rosario Alonso Ibáñez. La autora agradece a los evaluadores anónimos sus enriquecedores comentarios. 


\begin{abstract}
Integrated Urban Regeneration appears as a new model which should transcend sectorial approaches to urban systems to address the analysis, development, and evaluation of strategies from a multidisciplinary and citizen involvement approach. However, the tools or "indicator systems" developed up to date still lack an integrated vision, and the citizen is just a passive spectator, not and active part in the development of urban policies. The aim of this paper is channeling civil society participation and the pluridisciplinary approach recovering qualitative systems, through cognitive maps that complement the indicators systems developed up until today incorporating the real user's perception about the city.
\end{abstract}

Keywords: Integrated Urban Regeneration, cognitive maps, cualitative systems, citizen involvement, multidimensional approach.

\title{
Resumo
}

A Regeneração Urbana Integrada nasce como modelo que pretende ultrapassar as abordagens parciais dos sistemas urbanos para abordar a análise, o desenvolvimento de estratégias e a avaliação desde uma perspetiva multidisciplinar e de cidadania activa. No entanto, as ferramentas ou "sistemas de indicadores" desenvolvidos até hoje não têm ainda uma visão integrada, mantendo o cidadão como um mero espetador e não como parte ativa no desenvolvimento de políticas de desenvolvimento. Este artigo tem como objetivo canalizar essa participação dos cidadãos e esta visão multidisciplinar recuperando os sistemas de análise qualitativa, que através de mapas cognitivos, complementam os sistemas de indicadores desenvolvidos até agora integrando a verdadeira perceção do usuário sobre a cidade.

Palavras-chave: Regeneração Urbana Integrada, mapas cognitivos, análise qualitativa, cidadania activa, visão multidisciplinar

\section{Hacia la Regeneración urbana integrada}

Dos son los fenómenos observables en cuanto a la estructura espacial tras este último impacto de la globalización. Por un lado la consolidación de las "megaciudades", así definidas por Castells, que conectadas a redes globales son las responsables de la concentración de poder y del desarrollo económico, pero a la vez, también son el reflejo y las causantes de la desconexión social de ciertos sectores (CASTELLS, M., BORJA, J., 1998, p.52). Por otro lado, en áreas más desarrolladas como Norteamérica o Europa se está produciendo el fenómeno de dispersión, en el que unidades espaciales monofuncionales se separan de la ciudad y se extienden sobre el territorio apoyadas en una red de autopistas organizando la vida de forma polarizada. 
Los ministros responsables del desarrollo urbano de los Estados Miembros destacaban ya en la Carta de Leipzig la importancia de las ciudades en el equilibrio territorial tanto a nivel económico, como social, medioambiental y cultural. La inclusión en estas de los principios derivados del concepto desarrollo sostenible pasó a ser uno de los objetivos fundamentales de la Unión Europea, y con este, el desarrollo de todo un conjunto de documentos, estrategias, y sistemas de análisis que trataron de avanzar en la implantación de este nuevo modelo urbano y de superar los enfoques tradicionales sobre el territorio. Algunas investigaciones asocian el éxito del concepto desarrollo sostenible a su ambigüedad. La indeterminación que presentaba el término no favorecía la definición de unas metas claras, traduciéndose esto en una falta de puesta en práctica de acciones eficaces (NAREDO, J. M., 1997). Sin embargo, a pesar de la ambigüedad inherente al término, la definición de desarrollo sostenible correspondiente al informe "Our Common Future" o también conocido como "Informe Brundtland 1984"2, "entendido como aquél que satisface las necesidades actuales sin poner en peligro la capacidad de las generaciones futuras de satisfacer sus propias necesidades ${ }^{\prime 3}$, fue tomada como referencia en la implantación del nuevo modelo, dejando su huella en los documentos, y por tanto de los principios que habían de regir las políticas, estrategias, planes y proyectos desarrollados a nivel internacional encaminados a paliar el deterioro del medio humano.

El desarrollo sostenible implicaba la evolución desde la tradicional visión del suelo como recurso económico hacia un modelo que tuviera en cuenta su finitud, entendiendo que era necesario ahora centrarse en la evaluación y regeneración de lo existente en vez de en el desarrollo de nuevas áreas urbanas. Era por tanto necesario hacer un alto para analizar la situación actual, y coordinar a todos los agentes para alcanzar esta nueva orientación de los

${ }^{2}$ El Informe Brundtland presentó una nueva mirada al desarrollo sostenible. Elaborado por la Comisión Mundial sobre el Medio Ambiente y Desarrollo con el objetivo de establecer una agenda global para el cambio, se partió de la convicción de que es posible un futuro "más próspero, más justo y más seguro. Planteaba la posibilidad de un crecimiento económico basado en políticas de sostenibilidad y expansión de los recursos naturales. Tres fueron los objetivos fundamentales: examinar los temas críticos, promover formas de cooperación internacional y promover la comprensión y compromiso de los individuos, empresas, gobiernos, institutos y organizaciones Documento de la Comisión Mundial sobre Medio Ambiente y Desarrollo (1984): Informe Brundtland.

${ }^{3}$ Definición de desarrollo sostenible según fue enunciado en el Informe Brundtland, Informe que centraba su atención en los siguientes aspectos: población y recursos humanos, especies y ecosistemas, energía, industria, el reto urbano. Documento de la Comisión Mundial sobre Medio Ambiente y Desarrollo (1984): Informe Brundtland. 
sistemas urbanos. ¿Pero cuáles eran los factores a tener en cuenta en los desarrollos futuros? La división sectorial no ayudaba a la lectura del sistema urbano y de las interferencias entre las diferentes dimensiones y actores de las áreas urbanas. Era necesaria la lectura transversal de los diferentes factores para alcanzar un equilibrio real. El desarrollo urbano integrado es el término que a escala comunitaria se acuño para acoger esta visión pluridisciplinar, recomendando en la Carta de Leipzig “...tener en cuenta, simultánea y equitativamente, aquellas preocupaciones e intereses relevantes para el desarrollo urbano...", atendiendo para ello a "...la conciliación de intereses, facilitada por una política integrada de desarrollo urbano..."4.

Será finalmente en la Declaración de Toledo $2010^{5}$, encargada de desarrollar los acuerdos de la Carta de Leipzig, cuando estas políticas se condensen en un proceso denominado Regeneración Urbana Integrada (ALONSO IBAÑEZ, M.R., 2012). Apoyada por el Comité de las Regiones y el Consejo Económico y Social Europeo a través de los Dictámenes "El papel de la regeneración urbana integrada en el futuro del desarrollo urbano en Europa" y "La necesidad de aplicar un enfoque integrado a la regeneración urbana", ambos documentos aprobados en mayo de 2010, pretende generar respuestas a los problemas de los sistemas urbanos de manera convergente e igual eficiencia en todas las dimensiones cultural, medioambiental, social y económica.

Definida en el "Documento de Referencia de Toledo" (Documento de los Estados Miembros, 2010 : “Documento...), la Regeneración Urbana Integrada se concibió como "un proceso planificado que había de trascender los ámbitos y enfoques parciales hasta ahora habituales, para abordar la ciudad como totalidad funcional, y sus partes, como componentes del organismo urbano" (Documento de los Estados Miembros, 2010:

\footnotetext{
${ }^{4}$ Documento en el que se recogieron los acuerdos de la Reunión de Ministros responsables de Desarrollo Urbano de los Estados Miembros, Documento de los Estados Miembros (2007). Carta de Leipzig sobre ciudades europeas sostenibles, p.2.

${ }^{5}$ La declaración de Toledo es un documento que surge de la Reunión Informal de Ministros de Desarrollo Urbano de los países miembros de la UE, cuyo tema central fue la regeneración urbana integrada análisis de las ciudades europeas desde la múltiple dimensión de la sostenibilidad, entendiendo esta como una oportunidad para mantener un rumbo firme basado en los principios del desarrollo urbano integrado, inteligente, cohesivo, e inclusivo, como el único modo de conseguir una mayor competitividad económica, ecoeficiencia, cohesión social y progreso cívico en las ciudades europeas, así como de garantizar la calidad de vida y el bienestar de los ciudadanos en el presente y en el futuro. Documento de los Estados Miembros (2010). Declaración de Toledo, p.11
} 
“Documento...). En este documento las dimensiones “medioambiental, económica, social y cultural" aparecen definidas como factores imprescindibles a la hora de enfrentarnos con la complejidad de los sistemas urbanos. Ya desde ONU Habitat en la Declaración de Vancouver de 1976 se venía haciendo hincapié en la necesidad de mejorar los asentamientos humanos como elemento clave hacia la sostenibilidad entendiendo que el desarrollo económico y social era indisociable de los problemas asociados a estos (Documento de las Naciones Unidas Habitat, 1976). Esta asociación ciudad-problema económico, social, ambiental, cultural es el que llevó al proceso denominado como "europeización urbana", y a la necesidad de exploración de los asentamientos desde un proceso multidisciplinar que quedó asentado con la RUI. Sin embargo, tal y como anunció el Documento de síntesis sobre Regeneración Urbana Integrada, la RUI fue malinterpretada, y los Estados Miembros centraron su aplicación en fragmentos concretos y en temas sectoriales, perdiendo la visión integradora. EI SEPES, Entidad Pública Empresarial de Suelo organismo público adscrito al Ministerio de Fomento de España, desarrolló el documento sobre Modelos de Gestión de la Regeneración Urbana del 2011, que pretendió “establecer las líneas maestras para la puesta en marcha desde el Ministerio de Fomento de un programa de regeneración urbana de ámbito estatal". Este documento presenta este carácter parcial que venía siendo criticado de la mala interpretación de la Regeneración Urbana Integrada. Centrando su análisis en el estudio de tres programas, el "Empowerment Zones" de los Estados Unidos, el "Homes and Communities" de Reino Unido, y el "Programa Nacional de regeneración urbana y la ANRU" de Francia, que como apuntan en el Documento de Síntesis sobre Regeneración Urbana en Europa, carecen de la escala y carácter multidimensional necesarios por centrarse en áreas muy determinadas y atender a problemas muy específicos como pueden ser el tema de la vivienda, pierde el carácter integrado que venía siendo anunciado por la RUI (APARICIO MOURELO, A., 2011). Como resultado, siguiendo la corriente internacional, al igual que en EEUU, Reino Unido, y Francia, España apostó fuertemente por la reforma de fragmentos urbanos denominados ARIs.

Consolidada ya la Declaración de Toledo y el Documento que la acompaña podemos afirmar ya que el desarrollo sostenible integrado estaba plenamente definido y que existía consenso entre los objetivos comunes a los que se pretendía llegar. Sin embargo, no están tan claros los métodos que deben ser utilizados para conseguir tales fines. A pesar de que el 
documento identifica los elementos clave para la implantación del modelo integrado que pasarían por la elaboración de una estrategia, el acuerdo de compromisos compartidos en la dirección de la estrategia, la coordinación de la gobernanza para que el desarrollo de la estrategia y de los compromisos puedan llegar a buen término, articular todas las escalas temporales (corto, medio, largo plazo), y todas las escalas espaciales (región, área metropolitana, ciudad, barrio), e incorporar la participación ciudadana en todo el proceso, estas premisas son de difícil aplicación, por la magnitud de la intervención a la que hacen referencia y el alto grado de colaboración que requiere difícilmente asumible por los instrumentos y estructuras administrativas tradicionales (ALONSO IBAÑEZ, M.R. 2012, p.25). En el documento "¿Qué hace más productivas a las ciudades? Datos sobre el papel de la gobernanza en cinco países de la OECD”, hacen referencia a la complejidad que supondrá una reestructuración administrativa por el creciente desajuste existente entre estructuras administrativas y la realidad del espacio urbano.

Surge así el concepto gobernanza, que frente a un gobierno en que los asuntos públicos eran competencia exclusiva de los poderes políticos, propone fórmulas de gobierno más flexibles que incorporen a otros agentes en la formación y toma de decisiones por medio de procesos de participación y control. La principal aportación es el cambio de orientación del "poder sobre" hacia la "colaboración" (ALLI ARANGUREN, 2013, p.19-49). En 1995, el informe sobre gobernanza de las Naciones Unidas incorpora esta visión de integración definiéndola como "el conjunto de diferentes procesos y métodos a través de los cuales los individuos y las instituciones, públicas y privadas, gestionan los asuntos comunes". La Unión Europea ha establecido los principios para una cultura de gobierno orientada a la mayor integración entre los distintos rangos del poder público, la sociedad, y los ciudadanos. En el Documento de Toledo ya se incide en la necesidad de "coordinación horizontal" entre todos los actores que intervienen en el sistema urbano, haciendo hincapié en la necesaria implicación y participación del ciudadano. Sin embargo, aún en la actualidad se está sufriendo gran desorientación en la aplicación de la regeneración urbana integrada en la escala urbana europea. $Y$ es que, a pesar de la existencia de ese enfoque teórico comúnmente admitido, no se ha llegado a un enfoque práctico, es decir a un entendimiento de cómo gestionar, planificar, y evaluar el desarrollo sostenible integrado aplicable al conjunto de los estados miembros. En su artículo "De la política urbanística a la política 
urbana: los retos actuales del derecho urbanístico" $\mathrm{M}$ ạ Rosario Alonso Ibáñez hace referencia a la manifiesta dificultad en el ámbito jurídico de hacer operativo el desarrollo urbano sostenible.

A pesar de las dificultades, a partir de la consolidación del concepto de regeneración urbana integrada comenzaron los desarrollos de herramientas para su aplicación, más adelante denominados "sistemas de indicadores", que pretendían funcionar como la base para la creación y evaluación de las estrategias denominadas "estrategias de desarrollo integrado" en las diferentes escalas. Es evidente que un fallo en las herramientas de análisis afectaría a la validez del conjunto mermando la validez de las estrategias y su efectividad. Por tanto, es necesario analizar si los sistemas de indicadores actuales, encargados de elaborar y testar la implantación de la regeneración urbana están realmente respondiendo al carácter multidisciplinar y a una actuación coordinada de los diferentes actores.

En la Carta de Leipzig ya se hacía referencia como uno de los objetivos primordiales a la necesidad de una mayor implicación social afirmando que "la política integrada implica la participación de los agentes económicos, partes interesadas y el público en general", destacando que "cobran importancia con esta política los actores ajenos a la administración, buscando el papel activo del ciudadano" (Documento de los Estados Miembros, 2007, p.2). Sin embargo, esta integración de los diferentes actores es quizá una de las disfunciones que se aprecia con mayor claridad en los sistemas de análisis llevados a cabo hasta la actualidad. Ya desde la "Conferencia Internacional de la Biosfera, celebrada en París en 1968 comienza la confrontación entre la visión "ambiental" o desarrollista y la "ambiental-social". Encontramos esta dualidad en el informe de Medows del año 1972, titulado "Los límites del crecimiento", y en oposición a este, el elaborado por las ciudades latinoamericanas, el "Modelo Bariloche", como alternativa con un carácter más social que técnico (IDEA-PUCP, 1998, p.23). Y es que la equidistribución, y la toma de conciencia de las dificultades de todos los ciudadanos choca con la competencia entre ciudades y la carrera por la supremacía internacional. La globalización trajo consigo amenazas y oportunidades. Por un lado el acercamiento e integración globales, por otro una competencia desmedida, menos oportunidades para la mayoría y menos conocimiento de los problemas propios. Problemas que Saskia Sassen anuncia en su conferencia "Ciudad Global" del 8 de noviembre de 2011. 


\section{La evaluación observacional como análisis cualitativo}

Desde los sistemas de Indicadores Estructurales que acompañaban a la estrategia de Lisboa, pasando por los indicadores Presión-Estado-Respuesta de la OECD, hasta los Millenium Development Goals de las Naciones Unidas, o los Reference Framework Sustainable Cities de ámbito europeo, todos los sistemas de indicadores se han caracterizado por su carácter técnico y por la nula incorporación del usuario. Esta disociación entre técnico y usuario viene heredada de los sistemas de planificación tradicionales donde los estándares urbanísticos eran definidos por los agentes especializados en la ordenación territorial y urbana sin contar con la visión del usuario. Frente a esta dinámica que fue la que acompaño a las políticas públicas, encontramos otra que apuesta por la integración de la dimensión social en los procesos de planificación. En el Documento de Toledo se hace referencia a la dimensión social como aquella que atiende a los problemas de desigualdad destacando el desempleo, la reducción del abandono escolar, y la reducción del riesgo de pobreza, no es hasta bien entrado en el Documento de Referencia de Toledo que la dimensión social adquiere el papel de implicación de todos los actores con la coordinación horizontal. Siendo este matiz una de las diferencias fundamentales que debería haberse consolidado en el establecimiento de estrategias de regeneración urbana integrada, sigue sin embargo, aún hoy con escasa implicación práctica.

Ya en 1981 Craik definió dos sistemas de evaluación, evaluación técnica y evaluación observacional. La primera hacía referencia a indicadores basados en sistemas científicotécnicos y parece estar más consolidada en el estudio de la dimensión social. En cambio, la evaluación derivada de las impresiones recogidas por los sujetos (CORRALIZA, J. A., 1987, p.35) no acaba de adoptar una posición consolidada en el ámbito comunitario, pues a pesar de la apuesta por esta integración de los actores en el proceso de diseño de los asentamientos, los sistemas de indicadores que son de aplicación aún carecen de esta visión cualitativa. En definitiva, a pesar de existir un sistema observacional, que consiste en analizar el comportamiento y la experiencia humana en los escenarios en donde tiene lugar, este tipo de análisis donde el usuario toma partido no fueron incorporados a las herramientas de planificación desarrolladas por las administraciones públicas en la escala 
comunitaria, ni están siendo incorporadas en la actualidad en el avance hacia la Regeneración Urbana Integrada, a pesar de que tal y como apunta Ma Rosario Alonso Ibañez en las conclusiones al VI CIOT Fundicot "articular el cuerpo social en un proyecto ciudadano inclusivo" es uno de los elementos clave del enfoque integrado (ALONSO IBAÑEZ, M. R., 2011). Bien es cierto que existe una tendencia creciente a la humanización que puede verse claramente manifiesta en la evolución del modelo urbano Smart Cities hacia el Human Smart Cities. Este planteamiento surge con la intención de humanizar nuevamente una aplicación de las tecnologías que había sido desvinculada del usuario. El modelo human smart apuesta por fomentar el diálogo social sobre cuestiones urbanas apoyándose en las tecnologías. Y así fue expuesto en la presentación de las Human Smart Cities en la 2a Conferencia Europea sobre el futuro de Internet en Munich el 17 de Septiembre de 2014. En la publicación "The human Smart cities cookbook" (PERIPHÈRIA, 2014) editado en 2014 se insiste en ese "people in places".

A esta apuesta de Craik por la evaluación observacional se suman muchas otras aportaciones. Josep Muntañola considera indivisible cultura y evaluación afirmando que "la evaluación es válida tan solo dentro de los límites de una cultura y no existen variables universales que determinen a priori la correcta valoración de un edificio al margen de su situación geográfica e histórico social". Por tanto podemos afirmar que la aplicación de valores universales (estándares científicos universales) que puedan ser aplicados a la ciudad nos proporciona un análisis incompleto, ya que es a través del individuo como han de desarrollarse las aproximaciones del técnico hacia el sistema urbano. Los documentos europeos apoyan esta necesidad de cualificar en vez de exclusivamente cuantificar, sin embargo la balanza entre ambos tipos de análisis continua aun completamente desequilibrada tal y como afirma Muntañola (ARAGONES, J. I., CORRALIZA, J. A., 1988) "no estoy en contra de la cuantificación, que muchas veces es útil, sino a favor de la cualificación, y a favor de que se invierta tanto dinero en lo uno como en lo otro, y no solo en hacer estadísticas sin saber después el uso de los resultados, su significación". 
El Libro Blanco de la Sostenibilidad en el Planeamiento Urbanístico Español ${ }^{6}$, al igual que los documentos europeos, apuesta por un sistema de evaluación que permita reconocer los avances reales mediante el establecimiento de unos parámetros. La experiencia demuestra que la falta de objetivos claros y de una evaluación clara lleva al estancamiento o al incumplimiento de los principios que se pretenden alcanzar de ahí el énfasis de las metas existente en la Estrategia Europa 2020. Sin embargo, los problemas que podrían aparecer derivados de falta de cualificación de los sistemas de indicadores ya se sugerían en el Anexo 1 del Libro Blanco donde se nos advierte de los peligros que pueden derivarse de la cuantificación, entendiendo esta como el establecimiento de un solo límite de forma indiscriminada sin tener en cuenta cada contexto específico.

Es necesario comprender la importancia de incorporar el enfoque cualitativo a las herramientas de regeneración urbana integrada sin que esto se entienda como la necesidad de abandonar los sistemas cuantitativos existentes. Reichardt y Cook citados por Ma Teresa Anguera su artículo sobre "La investigación cualitativa", en 1979 ya hablaban de combinación de sistemas de evaluación cuando afirmaban que "un investigador no tiene por qué adherirse ciegamente a uno de los paradigmas polarizados que han recibido las denominaciones de "cualitativo" y "cuantitativo", sino que puede elegir libremente una mezcla de atributos de ambos paradigmas para atender mejor a las exigencias del problema de la investigación con que se enfrenta. La perspectiva cuantitativa "la explicación causal" se basa en unas hipótesis dadas, que podrán ser matizadas a través de la perspectiva cualitativa que estudia el fenómeno desde su complejidad. Parece entonces que no existe tampoco razón para elegir entre métodos cualitativos y cuantitativos."(ANGUERA ARGILAGA, M. T., 1986, p. 23-50).

\section{Los mapas cognitivos}

\footnotetext{
${ }^{6}$ El Libro Blanco es una publicación coordinada por la Dirección General de Suelo y Políticas Urbanas y que ha elaborado la Escuela Técnica Superior de Arquitectura, de la Universidad Politécnica de Madrid, a través de su Departamento de Urbanística y Ordenación del Territorio. Su finalidad estriba en servir de informe y guía, aportando un conjunto argumentado de propuestas de actuación, en este caso, con el fin de alcanzar una mayor sostenibilidad en el ámbito de la planificación urbanística. Ministerio de Vivienda, (2010): Libro Blanco de la sostenibilidad en el Planeamiento Urbanístico Español, Madrid.
} 
El planeamiento se ha apoyado a lo largo de la historia en diferentes instrumentos como fotografías aéreas, planos urbanísticos, históricos, y topográficos para la ordenación territorial y urbana. De este modo, cada una de estas herramientas aportaba una información cuantitativa concreta útil posteriormente en las fases de análisis, desarrollo, y seguimiento (figura1). La proliferación de análisis técnicos, como los levantamientos topográficos desarrollados por Coelho en el S. XIX, acercó las herramientas de análisis territorial a las representaciones a través de estructuras lógicas, alejándolas de las representaciones que tenían en cuenta el factor psicológico, estructura en la que se basan los “mapas mentales" (HERNÁNDEZ, L. A., FERNÁNDEZ MORALES, A., PEINADO CHECA, Z. J., 2012).

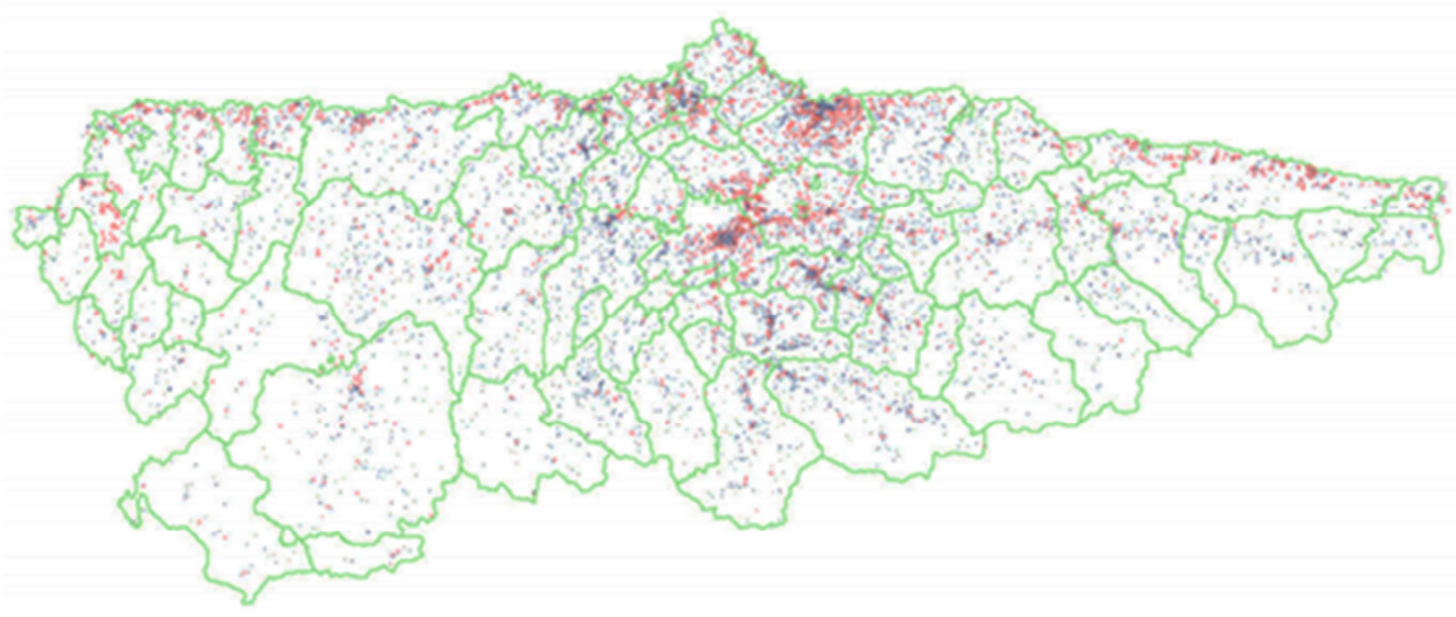

Figura 1. Mapa s/e de la cuantificación de la dispersión urbana en el Principado de Asturias. Fuente de origen Regiolab (REGIOLAB, 2013).

Sin embargo, el análisis de la ciudad no debe ceñirse exclusivamente al análisis de su base física. Los sistemas urbanos son el soporte de multitud de usuarios permanentes o esporádicos que dan lugar a "imaginarios urbanos", imágenes que cada uno de ellos efectúa sobre la ciudad y que representan el espacio según su percepción. Esto implica que la ciudad no sería una realidad en sí, sino la suma de múltiples realidades. Esta visión desde la diversidad es la que viene siendo apoyada desde el ámbito europeo con la regeneración urbana integrada y por tanto ha de complementar la gestión hasta ahora más técnica de la ordenación territorial y urbana. Teniendo en cuenta como explica Maurice Merleau en Fenomenología de la percepción, que "la cosa nunca puede estar separada de alguien que la perciba" ya que "jamás puede ser efectivamente en sí porque sus articulaciones son las 
mismas que las de nuestra existencia y se sitúa a la punta de una mirada, o al término de una explosión sensorial que la inviste de humanidad" (MERLEAU-PONTY, M., 2000, p.334), el análisis de la ciudad es igualmente indivisible de cada una de las percepciones individuales de sus usuarios, y por tanto, cada una de estas representaciones aporta información en el conocimiento del sistema urbano que es inseparable del proceso de planeamiento.

La percepción ambiental es un fenómeno de carácter social y podría paliar la deficiente incorporación de los sistemas cualitativos en los sistemas de indicadores que se están desarrollando en la actualidad para la elaboración de estrategias integradas, y por tanto, mejorar la comunicación actual entre el usuario y los agentes de la planificación. Este tipo de análisis fue utilizado por Armando Silva en su libro "Ciudades imaginadas", en el que emplea como método de análisis las representaciones cognitivas de los individuos que habían experimentado la ciudad. En esta publicación Armando desarrolla este aspecto de la ciudad vista desde la perspectiva del ciudadano y realiza un estudio empírico de la ciudad a través de las narraciones de los habitantes como una posible "categoría de análisis" (SILVA, A., 2006).

$Y$ es que los documentos europeos como la Declaración de Toledo ya anuncian esta necesidad de tener en cuenta el capital social en el avance hacia la RUI afirmando que "la base para la regeneración urbana es la ciudad existente, por tanto apoyándonos en el capital humano, social, material, cultural y económico acumulado en ella en el curso de la historia, se ira construyendo con esos elementos las ciudades eficientes, innovadoras, inteligentes, más sostenibles y socialmente integradas" (Documento de los Estados Miembros, 2010: “Documento..., p.10). Este proceso queda asociado al término Baukultur, entendiendo que "La Baukultur solo será posible si todos los involucrados en la planificación y la edificación se coordinan y si toda la sociedad en su conjunto asume la responsabilidad medioambiental también del espacio construido" (Documento del Ministerio de Vivienda alemán, 2010). Por tanto, debemos dejar que el ciudadano tome ese papel activo y de responsabilidad que le corresponde en la creación de la ciudad incluyéndolo en el proceso de planeamiento.

Este compromiso con la gobernanza ya aparece reflejado en la Carta de Leipzig 2007 donde hacen referencia a lo indisociable entre la aplicación de la RUI y el desarrollo de una gobernanza coherente con la misma cuando habla de la necesidad de "hacer uso de la 
herramienta de desarrollo urbano integrado y la gobernanza asociada para su puesta en marcha". Sin embargo, será en la Declaración de Toledo 2010 en el que encontremos mayor insistencia en relación con la necesidad de incorporar cambios en la gobernanza, y es que en esta declaración, la gobernanza aparece como una dimensión más a tener en cuenta en la definición de la nueva política territorial (TOLEDO, 2010), remitiéndonos para obtener información sobre esta al "Libro Blanco del Comité de las Regiones sobre Gobernanza Multinivel"(LIBRO BLANCO, 2009), donde queda desarrollada en profundidad la importancia de la gobernanza multinivel en la consecución de los objetivos de la regeneración integrada. ¿Qué medidas han sido planteadas para la incorporación del ciudadano en una gobernanza participativa, colaborativa? Una de los acercamientos posibles es a través de la cognición ambiental, y entre las estrategias más empleadas en la aplicación de la cognición ambiental se encuentran los "mapas cognitivos". Downs y Stea definían en 1978 el mapa cognitivo como "un constructo que abarca aquellos procesos que hacen posible a la gente adquirir, codificar, almacenar, recordar y manipular la información acerca de la naturaleza de su ambiente espacial. Esta información se refiere a los atributos y localizaciones relativas de la gente y los objetos en el ambiente, y es un componente esencial en los procesos adaptativos de la toma de decisión espacial" (ARAGONES, J. I., JIMÉNEZ BURILLO, F., 1986, p.67). Cabe destacar que el dibujo ya había sido hasta el S.XIX el elemento crucial de representación del paisaje urbano siendo las representaciones en forma de vista las más representativas (HERNÁNDEZ, L. A., FERNÁNDEZ MORALES, A., PEINADO CHECA, Z. J., 2012). Actualmente, los avances tecnológicos han permitido llegar a un nivel de precisión en el dibujo muy alto, a través del desarrollo de herramientas informáticas que, como los Sistemas de Información Geográfica, son capaces de almacenar en capas o estratos gran cantidad de información que posteriormente puede ser contrastada entre sí. El conjunto de capas es un conjunto de "mapas tematizados" (HERNÁNDEZ, L. A., FERNÁNDEZ MORALES, A., PEINADO CHECA, Z. J., 2012) que utilizan como base la cartografía. Los GIS son utilizados ya en la actualidad como sistemas de inventariado, análisis, y gestión. Muchos modelos urbanos como por ejemplo las Smart Cities han apostado por la simbiosis entre tecnología y análisis científico como método de acercamiento a la RUI ¿Qué pasaría entonces si gestionamos los mapas cognitivos a través de sistemas de información geográfica? 
El estudio de los mapas cognitivos lleva a la identificación de ciertos componentes que se repiten en los mismos: la "identidad" o identificación de un objeto, la "estructura" o relación espacial del objeto con el observador y otros objetos, y el "significado" emotivo o práctico que tienen estos elementos para el observador. Elementos que se relacionan con los términos sendas, bordes, barrios, nodos, y mojones que Kevin Lynch dejo definidos en su análisis de los urbanos en su libro "La imagen de la ciudad" LYNCH, K. (1984).

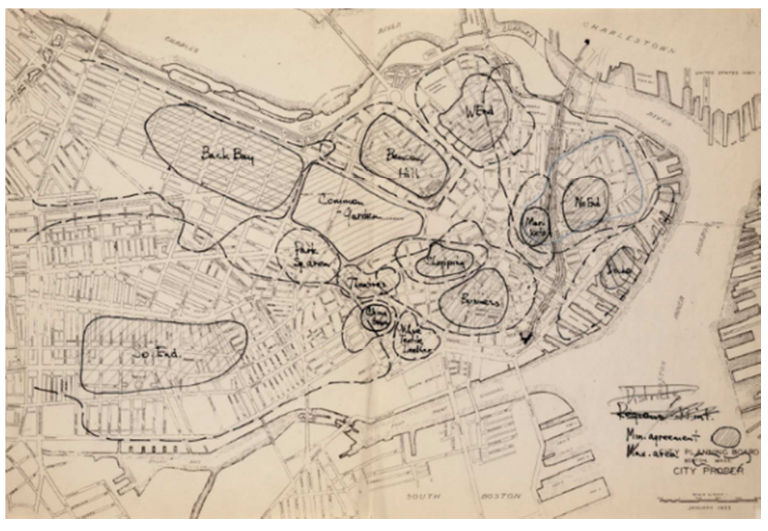

Figura 2. Bocetos para la imagen de Boston Lynch.

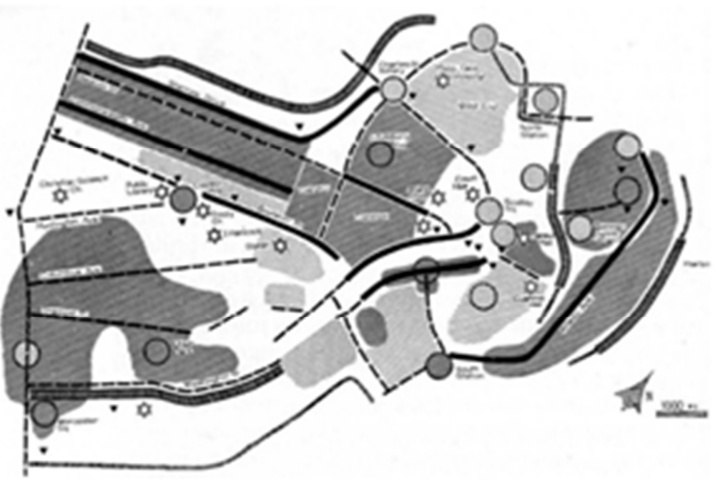

Figura 3. Mapa cognitivo Boston Kevin Lynch.

Estos elementos son fácilmente asumibles por los nuevos sistemas de representación geográfica siendo por tanto asumible su incorporación a los análisis que hasta hoy vienen siendo desarrollados por los técnicos en el desarrollo de estrategias de desarrollo urbano integrado. La combinación de los programas GIS con las nuevas capas temáticas de cada usuario mejorarían la actual relación entre los técnicos y el usuario, entre la percepción científica y la percepción real, es decir, equilibraría la balanza en la desproporción a la que Muntañola hacía referencia frente a sistemas cualitativos y cuantitativos, y le daría al ciudadano un papel activo. La superación del análisis urbano desde la percepción exclusiva del técnico apoya la visión de los nuevos modelos urbanos que como El Human Smart promueven el desarrollo de proyectos a través de la creación de grupos de trabajo locales que refuercen lo más posible la diversidad existente de forma que cada grupo solvente sus necesidades y se reafirme, y consolida la participación real que viene siendo aclamada desde la RUI. 


\section{Un ejemplo de contextualización de mapas cognitivos}

La sencillez que presenta la ejecución de los mapas cognitivos y la cercanía del dibujo a los ciudadanos hace de este método una herramienta muy versátil y universal en la recogida de datos sobre la percepción de la ciudad del usuario. Entendiendo que el desarrollo de un mapa es viable en tiempo y dificultad se promueve la iniciativa del desarrollo de mapas cognitivos de la ciudad de Avilés, Principado de Asturias, en España. La consulta se realiza a todo tipo de usuarios, desde los turistas esporádicos a los habitantes de diferentes áreas de la ciudad de diferente edad, sexo, etc., intentando abarcar una lectura lo más amplia y diversa posible que se aproxime a la participación real que promueve la RUI.

Las siguientes imágenes corresponden a diferentes mapas cognitivos realizados por usuarios de la ciudad de Avilés en Asturias. Cada una de ellas aporta una lectura diferente del sistema urbano, y a la vez todas ellas proporcionan multitud de información sobre la ciudad. Cada representación cognitiva de cada usuario incorpora los lugares para él reconocibles. Goethe dijo que "vemos solo aquello que conocemos", y ahí radica la utilidad de la incorporación de la lectura real del usuario. Cada uno representa los lugares simbólicos o que le son afines en la ciudad, y por tanto, nos muestra la ciudad que "existe" en realidad. Esta valoración realizada a través de la percepción del medio incorpora ya la dimensión afectiva y un plan de metas o expectativas del individuo, el último nivel correspondería con la adaptación del individuo con el propósito de obtener unas metas (CORRALIZA, J. A., 1987, p.42). Los mapas cognitivos mediante sus luces y sombras de las diferentes áreas de la ciudad permiten sacar conclusiones para la elaboración de estrategias de desarrollo integradas que a modo de "scaling up" (PERIPHÈRIA, 2014) aprovechen las fortalezas y mejoren las debilidades percibidas por los usuarios y canalicen la participación tal y como se demanda en el Documento de Referencia de Toledo.

De los mapas cognitivos de este fragmento urbano del Área Central de Asturias se obtienen gran cantidad de información sobre el significado real de la ciudad, sobre el uso y la percepción real. Encontramos fragmentos urbanos que aparecen dibujados por todos los usuarios repitiéndose reiteradamente en todos los mapas obtenidos tras el estudio, algunos de ellos adquieren tal protagonismo que el mapa elaborado por el usuario se ciñe exclusivamente a ellos o los detalla con mucha más exhaustividad que el resto de las áreas 
representadas. Un ejemplo de este simbolismo es la representación constante del "Parque de Ferrera" (figura 4,5,6), señalado en este caso con un cuadro rojo. Esta área verde es un elemento fundamental de la ciudad para todos los usuarios frente a otras áreas verdes de dimensión similar que en ocasiones ni siquiera aparecen en los mapas. ¿Qué pasa con el resto de áreas que permanecen ocultas, son áreas degradadas?, ¿Qué debemos hacer con los elementos patrimoniales que no son reconocibles por el usuario? ¿Podríamos recuperarlos para la memoria del usuario, para crear ciudad?

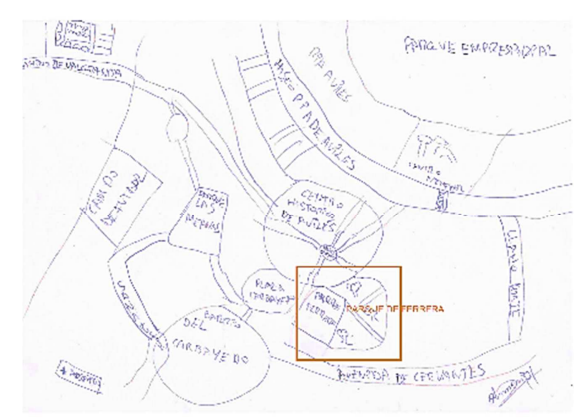

Figura 4. Mapa cognitivo 1

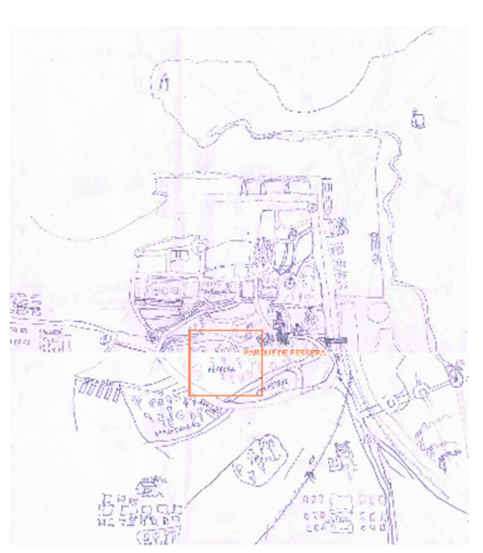

Figura 5. Mapa cognitivo 2

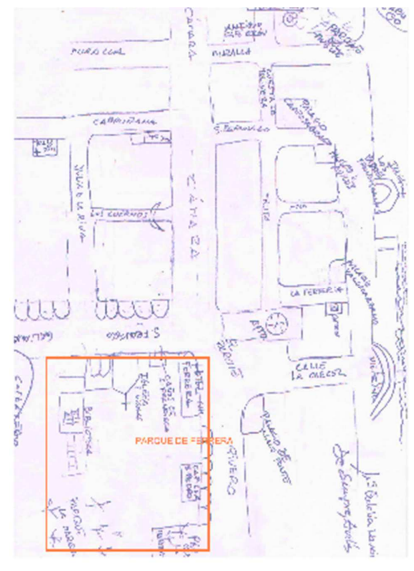

Figura 6. Mapa cognitivo 3

El carácter empírico del dibujo, que carece de una estrategia predefinida, hace que desde la disciplina urbanística no se haya tomado en consideración real como instrumento de análisis que acompañe a los sistemas de indicadores para la regeneración urbana actuales. Y es que tal y como pone de manifiesto Ma a Teresa Anguera, la dificultad para la aplicación que presentan los sistemas cualitativos es su "categorización", es decir, la adecuada lectura de la información obtenida, de las cualidades o atributos obtenidos sobre ese entorno. En su definición de los sistemas cualitativos afirma que solo a través del estudio de casos podríamos llegar a establecer una taxonomía adecuada al sistema cualitativo, es y que es necesario llegar a la mayor precisión posible ya que de estos depende la adecuada codificación de los datos (ANGUERA ARGILAGA, M. T., 1986, p. 23-50).

Cada vez son más los que apuestan nuevamente por la fusión entre las diferentes disciplinas, Muntañola (ARAGONES, J. I., CORRALIZA, J. A., 1988) destacaba ya en el año 1986 lo novedoso de la separación entre dos de ellas, arquitectura y psicología ambiental. Sin embargo, a pesar de que desde el ámbito europeo y en consonancia con el concepto de 
regeneración urbana integrada se apuesta por la recuperación del dialogo y la colaboración entre todas las disciplinas, ya que "no puede existir arquitectura sin sociedad ni sociedad sin arquitectura" (ARAGONES, J. I., CORRALIZA, J. A., 1988) y todas ellas influyen de algún u otro modo en el factor social, es evidente que este acercamiento entre las disciplinas que favorecería la coexistencia de sistemas de indicadores cualitativos y participativos aún no se ha producido en el ámbito de los instrumentos de planeamiento que se proponen desde el ámbito europeo. Cabe destacar que, al igual que en el proyecto de regeneración de "Coin Street" en Londres, destacado por el SEPES como una de las tres intervenciones modelo de la regeneración urbana integral por la activa participación ciudadana, la incorporación del uso de mapas cognitivos implicaría el acercamiento una metodología participativa acorde con los objetivos de la regeneración urbana integrada, y por tanto acercaría a las herramientas de planeamiento a la visión europea de cohesión.

\section{Representación cartográfica de mapas cognitivos}

¿Cómo podríamos descodificar los mapas cognitivos en su aplicación como herramientas de aplicación de la regeneración urbana integrada? Un mapa es una representación geométrica, plana, simplificada y convencional, de toda o parte de la superficie terrestre. Un mapa es una imagen incompleta, una construcción selectiva. Por tanto, las múltiples capas obtenidas de la lectura cognitiva aplicada a un contexto concreto darían lugar a múltiples mapas que representan según un usuario concreto la imagen de la ciudad. El cruce de las diferentes capas, al igual que los cruces de información realizados con GIS, daría lugar a un mapa que representaría la imagen de la ciudad por parte del colectivo que pretendamos seleccionar permitiendo obtener la lectura de los usuarios esporádicos, del usuario permanente, o de usuarios por edad, sexo, aficiones, trabajo.

Los cartogramas cuantitativos ya están siendo utilizados para representar, a través de sistemas diversos, datos que queremos describir derivados de los análisis técnicos actuales. Los análisis efectuados por la Agencia de Ecología Urbana de Barcelona son uno de los ejemplos claros de análisis ecosistémico a través de SIG. Estos sistemas apoyados en SIG podrían igualmente ayudarnos a obtener información de los mapas cognitivos si hacemos 
una lectura analítica de los mismos. Los mapas de puntos, lineales, o zonales son algunos de los tipos de mapas utilizados para la representación de variables. Aplicados a los mapas mentales estas estrategias de representación son de utilidad en el desencriptado de los mapas cognitivos y la obtención de conclusiones para el avance hacia la regeneración urbana integrada tal y como viene pidiéndose desde la escala comunitaria.

El análisis de los mapas cognitivos supondría un avance sobre la integración de todas las dimensiones urbanas en tanto representa la visión transversal de la lectura que cada usuario hace de la ciudad. La dimensión social, ya que plasma los problemas sociales y favorece implicación del usuario en el desarrollo de estrategias futuras. La dimensión cultural a través de la lectura de la ciudad por los diferentes grupos culturales, y el conocimiento de la percepción real del patrimonio cultural para la posible reutilización del mismo en la regeneración urbana. La dimensión medioambiental a través de la imagen de proximidad o lejanía de los sistemas verdes y su accesibilidad, y el adecuado tamaño de los mismos por la escala de su representación. Y la dimensión económica en tanto da a conocer las áreas potencialmente transitadas, y las áreas abandonadas, irreconocibles por el usuario, o degradadas. Además de esto, las imágenes de las ciudades soy hoy la principal vía de comunicación con el usuario. No es ajeno el uso de la imagen como sistema de marketing de un destino turístico. Por tanto, la plasmación de la imagen mental que cada usuario percibe de la ciudad de estudio, así como el mapa resultante del análisis conjunto son herramientas muy valiosas en la toma de conciencia del espacio público por parte del ciudadano, por proporcionarnos la imagen del icono de ciudad que estamos presentando a los usuarios. Los mapas anamórficos, podrían funcionar como gráfico analítico resultante del estudio de los diferentes mapas cognitivos. Estos, a pesar de ser muy criticados como herramienta científica, son sin embargo, muy descriptivos y didácticos en su comunicación con el usuario permitiendo un dialogo fluido entre el técnico y los ciudadanos, y facilitando por tanto la coordinación horizontal que promueve la Unión Europea.

Actualmente los ciudadanos se preguntan "para quién, con quién, y como" se ha hecho la ciudad (Grupo de Estudios Jurídico-Sociales ), y es que desde los foros científicos se defiende desde hace décadas la necesidad de incorporación de estos sistemas cualitativos sin haber obtenido respuesta. En las I Jornadas de Psicología ambiental de Madrid, Muntañola recomendaba "estudiar más las pautas de habitar espacios, para aprender luego de ellas los 
mejores y más sutiles medios de análisis" (ARAGONES, J. I., JIMÉNEZ BURILLO, F., 1986). Y en cierto modo esta es la deficiencia que aún hoy muestran los procesos de planificación, que a pesar de apostar por la Regeneración Urbana Integrada como nuevo modelo con un enfoque global, no han sabido conectar con el usuario de la ciudad en los actuales sistemas de indicadores encargados de desarrollar las estrategias de desarrollo urbano integrado. Apostemos entonces por "estudiar más el mundo para conocer el espacio, y menos el espacio para producir mundos" (ARAGONES, J. I., JIMÉNEZ BURILLO, F., 1986).

\section{Referencias}

\section{Libros:}

APARICIO MOURELO, A., DI NANNI, R. (2011): Modelos de Gestión de la Regeneración urbana, SEPES, Madrid. ARAGONES, J. I., JIMÉNEZ BURILLO, F. (1986): Introducción a la psicología ambiental, Madrid, 1986, Ed. Alianza psicología.

ARAGONES, J. I., CORRALIZA, J. A. (1988): Comportamiento y medio ambiente: La psicología ambiental en España, Comunidad de Madrid consejería de política territorial, Madrid.

CASTELLS, M., BORJA, J. (1998): Local y global. La gestión de las ciudades en la era de la información, ed. Taurus, Madrid.

CORRALIZA, J. A. (1987): La experiencia del ambiente. Percepción y significado del medio construido, Tecnos, Madrid.

LYNCH, K. (1984): La imagen de la ciudad, GG, Barcelona.

MERLEAU-PONTY, Maurice, Fenomenología de la percepción. Barcelona, Península, 2000

PERIPHÈRIA, The Human Smart Cities CookBook, Planum. The journal of urbanism, nํ28 vol I, 2014.

SILVA, A. (2006): Imaginarios urbanos, Arango Editores, Bogotá

\section{Artículos:}

ALLI ARANGUREN, Juan-Cruz, "Gobernanza Europea”, Monografías de la Revista Aragonesa de Administración Pública, ISSN 1133-4797, XIV, Zaragoza, 2013, p. 19-49.

ALONSO IBAÑEZ, M.R. (2011): "Regeneración urbana integrada”, en Crisis y Territorio. Aportaciones y Conclusiones del VI Congreso Internacional de Ordenación del Territorio. FUNDICOT. ISBN: 978-84-695-0795-7

ALONSO IBAÑEZ, M.R. (2012): “De la política urbanística a la política urbana: los retos actuales del derecho urbanístico", Revista de Derecho Urbanístico y medio ambiente, nํ277, noviembre.

ANGUERA ARGILAGA, M. T. (1986): “La investigación cualitativa”, Educar 10, 1986

HERNÁNDEZ, L. A., FERNÁNDEZ MORALES, A., PEINADO CHECA, Z. J. (2012): “El análisis del paisaje urbano a través del dibujo", 4IAU 4a Jornadas Internacionales sobre Investigación en Arquitectura y Urbanismo", Valencia, ISBN 978-84-938670-5-8.

IDEA-PUCP (1998): “Agenda 21: desarrollo sostenible: un programa para la acción"

NAREDO, J. M. (1997): "Sobre el origen, el uso y el contenido del término sostenible". 
REGIOLAB (2013), “Descripción y análisis de la huella urbanística del boom inmobiliario en Asturias mediante Sistemas de Información Geográfica, 1996-2006", Investigaciones regionales, 27.

\section{Documentos:}

DOCUMENTO DE LA COMISIÓN MUNDIAL SOBRE MEDIO AMBIENTE Y DESARROLLO (1984): Informe Brundtland.

DOCUMENTO DE LAS NACIONES UNIDAS HABITAT (1976): Declaración de Vancouver sobre asentamientos humanos, de la Conferencia de las Naciones Unidas sobre asentamientos humanos, 31-05-1976.

DOCUMENTO DE LOS ESTADOS MIEMBROS (2007). Carta de Leipzig sobre ciudades europeas sostenibles.

DOCUMENTO DE LOS ESTADOS MIEMBROS (2010). Declaración de Toledo.

DOCUMENTO DE LOS ESTADOS MIEMBROS (2010). Documento de Referencia de Toledo sobre la regeneración urbana integrada y su potencial estratégico para un desarrollo urbano más inteligente, sostenible y socialmente inclusivo en Europa, incluido en: Documento de los Estados Miembros (2010). Declaración de Toledo.

Grupo de Estudios Jurídico-Sociales Sobre Territorio y Desarrollo Sostenible, Regeneración Urbanística y territorial. Oviedo, publicado en la web:

http://www.unioviedo.es/Desarrollosostenible/informacion/documentos/Texto\%20Foro\%200viedo.pdf

MINISTERIO DE VIVIENDA, (2010): Libro Blanco de la sostenibilidad en el Planeamiento Urbanístico Español, Madrid

MINISTERIO DE VIVIENDA ALEMAN (2010): Baukultur Planning and building in Germany. 